ELK ASIA PACIFIC JOURNAL OF SOCIAL SCIENCES

ISSN 2394-9392 (Online); DOI: 10.16962/EAPJSS/issn.2394-9392/2014; Volume 2 Issue 2 (2016)

ELK

Asia Pacific Journals

www.elkjournals.com

\title{
STUDENT ATTRITION IN ADILABAD DISTRICT TELANGANA: INCIDENCE, INFLUENTIAL FACTORS AND PREVENTIVE STRATEGIES
}

\begin{tabular}{|c|c|}
\hline B.LAXMAIAH & Dr. GURMEET SINGH KACHOORA \\
M.A, M.Ed, M.Phil, Research Scholar, OPJS & M.A, M.Ed, PhD, OPJS University, Churu, \\
University, Churu, Rajasthan & Rajasthan \\
\hline
\end{tabular}

\begin{abstract}
The alarmingly high rate of illiteracy among the students at high school level, along with the increasing number of drop outs, is reason enough to carefully explore the factors leading to such results. This is essential for identifying and understanding the social groups that are more vulnerable to dropouts, in order to improve the efficiency and reduce the wastage of education system. The purpose of this study is to identify the factors that influence the drop out of students from schools, with specific reference to the Adilabad district in Telangana, India and propose school strengthening programs. To gain an insight on this impending issue, close-ended questionnaires were distributed among 100 drop out students and interviews were held with 15 teachers from the schools of Telungana District, Andhra Pradesh. It was concluded from the study that factors of socio economy (illiteracy, poverty, child labor etc.), teacher related factors (harsh attitude, corporal punishment, teacher shortage etc.), personal factors (learning issues, lack of concern, health etc.), curricula and pedagogy related factors (unpleasant surrounding of school and classes, unattractive books etc.), infrastructure related factors (lack of physical facilities like chair or school desk etc.) were major factors influencing the dropout of students from schools. The research further recommends strategies that can be useful for the schools to retain their students.
\end{abstract}

Keywords: Illiteracy, Adilabad, Dropout of Students, Child Labor

\section{Introduction}

The most fearful fact about the Education in India is that no matter how much emphasis is laid on education, knowledge, and literacy, the phenomenon of 'drop out' is prevalent as a continuing process which is adding up to the huge population of drop outs (Pramanik and Nangia, 2010). As stated by Basumatary (2012), offering the right type of education at the right time and to the right people forms the key to formation of effective human 


\section{ELK ASIA PACIFIC JOURNAL OF SOCIAL SCIENCES}

ISSN 2394-9392 (Online); DOI: 10.16962/EAPJSS/issn.2394-9392/2014; Volume 2 Issue 2 (2016)

resource. In this regard, a UNESCO report (2000) on the state of the world's children, points out, that about one thirty million children in the developing world denied their right to education through Dropping out. Therefore, to solve this recurring issue of student attrition/dropouts is a must for India to develop as a knowledge-efficient, selfsufficient, developed country.

Dropping out of school is a well-documented social problem and often present daunting circumstances for adolescents (Jana et al., 2014). The social outlay of dropout problem comprises an under practiced effort strength, lower production, mislaid taxes and increased public assistance and crime (Arif et al., 2003). Dropout in general terms is defined as the instance where children who have been to school earlier happen to stop themselves, resulting in not completing their courses at school (Basumatary, 2012). The rate of school dropouts in India has never been small (Anugula and Shantha, 2010). In fact, drop out is becoming a universal phenomenon of the education system of India and it is also claimed that, school dropout is spreading over all the levels of education and in all the parts of the country (Chugh, 2011).
The data for 2013-14 academic year collected across the 10 districts of Telangana presents a pathetic account of primary education in the state. Even before the completion of five years of education(Class I to V), a whopping 22.32 per cent students drop out of school while it is paltry 3.20 percentage in Andhra Pradesh (Indian Express, 2014).

The present accelerating school dropout problem is a leading economic and social issue that poses complex subject for educators, policy makers, students, counsellors, parents and others (Josephine and Vivian, 2014).

\subsection{Aim of the Study}

The aim of the research is to study the school strengthen programs and to stop drop outs at high school level with specific emphasis on the Adilabad district, Telangana.

\subsection{Research Objective}

The following are the objectives of the research

- To identify the factors that influence drop out of students from schools, especially in the Adilabad dist. Telangana

- To identify the challenges faced by the schools in Adilabad dist. Telangana, 


\section{ELK ASIA PACIFIC JOURNAL OF SOCIAL SCIENCES}

ISSN 2394-9392 (Online); DOI: 10.16962/EAPJSS/issn.2394-9392/2014; Volume 2 Issue 2 (2016)

leading to increased drop out of students

- To analyze the steps and suggest strategies to strengthen the schools and educational programs with the aim to prevent the drop out of students from schools

\section{Literature Review}

\subsection{Student Dropouts from Schools}

Student retention has emerged as the most important aspect for institutions in terms of accountability and rankings. The accountability of universities is increasingly recognized and associated with its graduation rates (Field, 2006).

Sharma, Ruchita, Sharma and Nagar (2007) have asserted that despite of the increasing percentage of literate population in India, it is surprising that the number of illiterate children between the age group 6 to 14 years is also rising drastically. This has been further claimed by Pandita (2015), by statically showing a wide gap between the enrollment and dropout rates of school children during the period $2001-2002$ to $2010-2011$. The study showed that as opposed to 38.16 per cent and 58.70 per cent increase with respect to the enrolment of students for the upper primary level and the secondary level respectively, the drop out of students reported a 58.80 per cent and 79.95 per cent, as they entered the upper primary level and secondary level.

\subsection{Factors influencing Students Dropouts}

Much literature on Student attrition, retention, and the like have focused on the outcomes of various collegiate academic characteristics, which have further shaped the national initiatives to be taken. Apart from the academic features, the stated goal of much of the student retention literature is to identify atrisk students, using demographics and precollege measures of academic ability (e.g. ACT/SAT scores) and measures of student/institutional fit (Radcliffe et al., 2006).

Govindaraju and Venkatesan (2010) stated that, there can be a number of reasons for dropping out of children from schools, such as, non-availability of schools, failure in academics, pushing out due to behavior of the teachers or the school environment, inaccessibility of schools, financial problems etc.

The literature exposed that there were numerous reasons for student attrition in India, which can be further categorized into major themes. Family Issues are one of the major 


\section{ELK ASIA PACIFIC JOURNAL OF SOCIAL SCIENCES}

ISSN 2394-9392 (Online); DOI: 10.16962/EAPJSS/issn.2394-9392/2014; Volume 2 Issue 2 (2016)

reasons which result in student dropouts from school. Pratham Delhi (2008) noted that some of the vital reasons were migration of the families of the students to other places especially remote areas with no access to schools; removal of students from the schools due to long absenteeism; difficulty in commuting for the students from their place of stay to the schools; need for special care for certain students and absence of such schools in that locality; family crisis such as financial issues, sick parents; working parents at home and making the students take care of the younger siblings; children working to support their family financially, etc. The major familyrelated reasons cited by the households for the dropout in a study conducted by gathering data from the National Family Health Survey-3, by Gouda and Sekher (2014), were "children were not interested in studies", "cost was too much", "children were required for household work" and also for "work outside to contribute to family income". Another study by Baruah and Goswami (2012) discussed about the reason for dropouts in Telangana schools and found out that a whopping 82.50 per cent of the respondents reported that large family size is one of the reasons, which encourages them for getting engaged with work by their parents rather than attending the schools.
Other chief reasons for student drop outs are considered to be other social and economic problems stated by Pratinidhi, Warerkar and Garad (1992) as, higher costs for education; child marriage; inability to get admission; lack of safety to send girls to school; no proper facilities for girls at schools in remote areas and no female teacher. In addition, the reasons were also related to religion; caste; place of residence; household size of the students; standard of living; education of parents; working status of the parents; occupation of the head of the family; exposure to mass media etc. Kandasamy et al (2013) noted that the child labor and abduction emerged as the reason for school dropout taken from the case study of 700 school dropout is child labor. Further, the study reported that the female students were discouraged due to cases of being sexually exploited, prevalent gender discrimination, child marriage and closed attitude towards them.

A major segment of the literature talks about issues such as attitudes of students and their overall interest in studying as a reason for student attrition. It has been shown from the study of Radcliffe et al., (2006) that living off campus during the first term of enrollment lowers the predicted probability of graduation, pointing towards the importance of a student's 


\section{ELK ASIA PACIFIC JOURNAL OF SOCIAL SCIENCES}

ISSN 2394-9392 (Online); DOI: 10.16962/EAPJSS/issn.2394-9392/2014; Volume 2 Issue 2 (2016)

social integration on campus which develops the overall attitude of a student towards the institution. Academic disengagement and a loss of academic motivation were seen to result in the students failing to attend lectures and reporting a loss of interest, motivation, and even a sense of personal failure in a study conducted by Redmon et al., (2011) involving a qualitative investigation into the reasons why students exit from the first year of their programme and UCD. This was often the case as a result of not being in their preferred course and experiencing academic difficulties.

\subsection{Steps and Strategies to strengthen the schools and educational programs}

Anguiano (2006) has highlighted the importance of the students remaining motivated towards their studies, a major part of which relies on their teachers who must act as a facilitator and support the autonomy of students. Motivation programs such as regular, positive feedback of information, contribute by enhancing the perceived competence and their intrinsic motivation. Co-curricular activities were another aspect of school teaching which was recognized by Arif et al., (2003) and which must be started in high schools on large scale to engage the attention of students in their daily programs.
Jeynes (2007) has asserted that if there is less contribution of parent's interest for their Childs' education then there are greater possibilities of student dropouts. Brown (2013) has further stated that the parent teacher meeting has been commonly used to reduce high school students drop out rate.

In a study conducted by Arif et al., (2003), among two primary schools in West Bengal, it was found out that most of the parents of this district were below the poverty line. Therefore, the researchers recommended that the government must give greater amounts of scholarships to the poor students, along with non-financial help in the way of reduced and controlled prices for stationery needed for schooling, school uniform, shoes, etc. Wagle (2012) has stated that scholarships and incentives have a positive influence on the students and helps to bring them back to school and managing them until the completion of the whole cycled education.

Hussain and Salfi (2011) have indicated that the most sought-after aim of the education system is delivering quality education at all levels. Arif et al. (2003) have recommended that the government must ensure that the educational institutions are adept with basic facilities like drinking water, electricity, toilet, 


\section{ELK ASIA PACIFIC JOURNAL OF SOCIAL SCIENCES}

ISSN 2394-9392 (Online); DOI: 10.16962/EAPJSS/issn.2394-9392/2014; Volume 2 Issue 2 (2016)

sitting mats, furniture, and black boards on priority bases. Further, apart from the infrastructural needs of institutions, it is also recognized that students need to be provided with Educational awareness programs aimed at adults so as to keep them interested in the field of studying.

\section{Hypothesis for the Study}

- Null Hypothesis: Attitude of students is not a reason for drop outs at high school level on the Adilabad dist, Telangana

Alternative Hypothesis: Attitude of students is the main reason for drop outs at high school level on the Adilabad dist, Telangana

- Null Hypothesis: Social and economic problems is not a reason for drop outs at high school level on the Adilabad dist, Telangana

Alternative Hypothesis: Social and economic problems is the main reason for drop outs at high school level on the Adilabad dist, Telangana

- Null Hypothesis: Lack of personal interest is not a reason for drop outs at high school level on the Adilabad dist, Telangana
Alternative Hypothesis: Lack of personal interest is the main reason for drop outs at high school level on the Adilabad dist, Telangana

- Null Hypothesis: Family related issues is not a reason for drop outs at high school level on the Adilabad dist, Telangana

Alternative Hypothesis: Family related issues is the main reason for drop outs at high school level on the Adilabad dist, Telangana

- Null Hypothesis: Motivation and support programmes adopted at high school level on the Adilabad dist, Telangana does not prevent dropouts

Alternative Hypothesis: Motivation and support programmes adopted at high school level on the Adilabad dist, Telangana prevents dropouts

- Null Hypothesis: Parent - teacher meetings adopted at high school level on the Adilabad dist, Telangana does not prevent dropouts

Alternative Hypothesis: Parent teacher meetings adopted at high school level on the Adilabad dist, Telangana prevents dropouts

- Null Hypothesis: Scholarships schemes adopted at high school level on the 


\section{ELK ASIA PACIFIC JOURNAL OF SOCIAL SCIENCES}

ISSN 2394-9392 (Online); DOI: 10.16962/EAPJSS/issn.2394-9392/2014; Volume 2 Issue 2 (2016)

Adilabad dist, Telangana does not prevent dropouts

Alternative Hypothesis: Scholarships schemes adopted at high school level on the Adilabad dist, Telangana prevents dropouts

- Null Hypothesis: Improved quality in education adopted at high school level on the Adilabad dist, Telangana does not prevent dropouts

Alternative Hypothesis: Improved quality in education adopted at high school level on the Adilabad dist, Telangana prevents dropouts.

\section{Conceptual Framework:}

The following figure illustrates the conceptual framework considered for the present study. It displays that the issues of student attrition at high school level are social and economic problems, attitude of students, family related issues and lack of personal interest. Further, to resolve these issues of student dropouts, the recommended precautionary steps that can be adopted are namely; motivation and support programs, parent teacher meetings, scholarship schemes, and improved quality in education.

\section{(Refer Figure 1 Here)}

\section{Research Methodology}

This study incorporates both Interpretivism and positivism, i.e. it adopts Realism. Further, for the research design, it makes the utilization of a descriptive research design, since the descriptive research "endeavors to portray the issue, circumstance, administration, and circumstance or program methodically and offers data about the living states of a group or describes mentalities towards the issue" (Thyer, 2009).

Both the probability and non-probability methods of sampling have been used for selecting the sample for the present study, since this investigation carries out both qualitative and quantitative evaluations. For the subjective study, it utilized the convenience sampling method to avail its benefits of making the information-gathering simple and less tedious. Whereas, for the quantitative examination probability sampling was utilized.

The target population for the qualitative study is the 15 teachers of the high schools in Telangana whose view can support the study to analyze the dropouts of students. The quantitative study makes survey collection 


\section{ELK ASIA PACIFIC JOURNAL OF SOCIAL SCIENCES}

ISSN 2394-9392 (Online); DOI: 10.16962/EAPJSS/issn.2394-9392/2014; Volume 2 Issue 2 (2016)

from 100 drop out students from the schools of Telangana District, Andhra Pradesh. Openended questionnaires will be deployed to collect primary data and the children will be surveyed using close-ended questionnaires. The study utilizes the accompanying measurable devices for the quantitative information examination, such as the Graphical method, Karl Pearson Correlation coefficient, and Simple percentage method. Further, the data will be statistically analyzed and presented by using SPSS and Microsoft Excel.

\section{Results and Discussion}

\subsection{Quantitative}

A majority of the sampled respondents $(61.3 \%)$ were males. The samples were further majorly found to be belonging to the age group category $15-17$ years, with $72.7 \%$ reporting that they had a family size of 3-5 members.

For the schools in Adilabad, Telangana, the increasing student dropout rate is a major critical issue. This was recognized by a wide majority of $86 \%$ of the respondents. The study sample revealed that about $61 \%$ of them, agreed that they are not interested to continue their studies.
Concerning the factors which result in students to drop out from their schools, almost all the respondents in this study reported that the impact of poverty and economic status makes them to drop out at high school level in Adilabad district Telangana. Also, it was mentioned that $43.3 \%$ of the respondents felt that according to them, economic problem is a major reason that makes them to drop-out at the high school level in Adilabad district, Telangana. This finding is in line with the similar claim made by Baydu et al. (2013) and Ingrum (2006), who have asserted that the relative socio economic status of the student, influences the rate of dropout. Concerning the overall poverty level of the family, it was inferred from the study that majority agreed that poverty in their family forced them to quit their studies. About $69 \%$ of the respondents also agreed/strongly agreed that their family background forced them to drop-out from school, with a further $52 \%$ reporting that their family is economically not fit to support their education.

Apart from the economic issues, the data revealed that there were several other reasons which led to student dropouts. One such factor was the 'fear about school and exams', which was reported by about $36.7 \%$ of the 


\section{ELK ASIA PACIFIC JOURNAL OF SOCIAL SCIENCES}

ISSN 2394-9392 (Online); DOI: 10.16962/EAPJSS/issn.2394-9392/2014; Volume 2 Issue 2 (2016)

respondents. This fear has often been related with crimes in schools, as claimed by several studies such as Quarles and Quarles (2011). However, this in opposition to the majority of the respondents $(63.3 \%)$ strongly disagreeing that they drop-out from school due to physical abuse, or sexual abuse (48\%). Further, the association of fear of failing in exams has also led to fear from the schools, and thereby leading to dropouts. About $28 \%$ of the respondents also reported that the distance between their school and village is the major reason that makes them to discontinue their studies.

Regarding the personal habits or other factors, related to the students, and it further impact on their decision to dropout, the study revealed that $72.7 \%$ of the respondents strongly disagreed that they are drug addicted and so they are not interested in going school. Further, the most astonishing finding revealed that more than half of the respondents agreed that they are not interested to continue their studies. However, they also disagreed on factors such as the illness of family members, migration of parents, gender discrimination, to have any effect on their decision to drop out from school. The study finding pointing that the major reason for student's being disinterested in the school, is that they are unable to score good marks (reported by about 49\%), and the feeling that it is very difficult for them to pass in all subjects, indicates that there is a need for motivation, and a greater attention on the weaker students of the class. This is also supported by the disagreement shown by $48 \%$ of the respondents that they do not like their teachers and school. Thus, giving the boost for enhancing their school experiences and motivation to continue their studies.

Given the vast number of students dropping out of schools, the schools in Adilabad are seen to adopt various steps so as to curb this rising trend. This was also recognized by more than half of the respondents, who expressed that their schools are taking steps to control the drop-out of students. However, the study findings have highlighted a set of challenges faced by these schools, in order to reduce or tackle the present problem of student dropouts in Adilabad. The greatest challenge that came forward from the results, reported by about $49.3 \%$ of respondents, is that there is a lack of awareness about school education, which has become the major reason for students deciding to drop-out from the school.

In terms of the loss to school's resources, it was inferred from the study that $58.7 \%$ of the 


\section{ELK ASIA PACIFIC JOURNAL OF SOCIAL SCIENCES}

ISSN 2394-9392 (Online); DOI: 10.16962/EAPJSS/issn.2394-9392/2014; Volume 2 Issue 2 (2016)

respondents expressed that according to them, the challenge of 'wasting their resources' is faced by the schools, due to the increased drop out of students. This was also reported by the study conducted by Hudson (2013), who stated that the schools had to face developmental setbacks and wastage of resources due to such students.

The findings have revealed that despite of a majority being satisfied with the steps and strategies followed at schools to control and stop drop-outs $(60 \%)$, the role of teachers is given a priority by the students in overcoming the present issue of student dropout. The major reason is that despite of the steps being taken, there is a lack of support and motivation $(48.7 \%)$. More than half of the respondents also felt that, it is important for teachers to make parents to realize about their role in their children education. However, on the contrary, what is noticed in fact is that a majority reporting that neither the teachers analyze the problems of students, nor do they help them to recover from it which makes them to drop-out from the school. It was further reported by more than half of the respondents, that the teachers and school must take collaborative effort to improve the quality of education to students. A similar importance of the school based interventions, was also highlighted by the study done by Ungar, Russell and Connelly (2014), with the aim to enhance the resilience of the students. One such effort which came to the forefront, is the that the government and school should provide scholarships to support the education of students, reported by a clear majority of $85.3 \%$ respondents. $65.3 \%$ of the respondents also suggested that the school must link NGOs programs to support the students education. Also, an increasing importance should be placed on organizing parent and teachers meetings, which was also recognized by about $54.7 \%$ of the respondents. They reported that it helps parent to knows about the importance of education to students. Another major need that arose from the findings was that there was a need felt for make parents to realize about crime of child labor $(46.7 \%)$. Concerning the motivation level of the students, recommendations such as allowing group studies and other programs (66.7\%), motivation by teachers to enhance learning ability through various activities $(68 \%)$, were put forward by the respondents.

\subsection{Qualitative}

The qualitative research carried out with the teachers, revealed a set of issues which were faced by them while trying to prevent students 


\section{ELK ASIA PACIFIC JOURNAL OF SOCIAL SCIENCES}

ISSN 2394-9392 (Online); DOI: 10.16962/EAPJSS/issn.2394-9392/2014; Volume 2 Issue 2 (2016)

dropout, and also problems faced due to student dropouts.

The teachers revealed that the factors such as poverty, going for work, lack of interest, death of father, prolonged illness, fear of punishment, early marriage, poor teaching, doing job of parents, neglect of parent, accident and lack of qualification among teachers, are among the most influential reasons for student dropouts in Adilabad. Similar to the findings of the quantitative research, the teachers also reported that the socioeconomic condition, past academic performance of the students, parent's educational level achieved, hinder the student dropouts. Other factors related to the teachers and school facilities, were teacher absenteeism, dearth of trained and skilled teachers, fear of punishment from the teachers. Concerning the simultaneous problems faced by teachers in school due to the present scenario of rising student dropouts, it was noticed that student verbal abuse of teachers as well as the student physical abuse of teachers was the most disturbing incidents reported. Not only this, there was also the incidence of reduced wages being given to the teachers than their town counterparts.
Apart from the teachers, the schools are also fund to face extreme challenges due to the student dropouts. The research conducted with the teachers, revealed a close association between student dropouts and teacher dropouts, taking a serious toll on the school's overall functioning.

It was recognized that an urgent solution to tackle the present situation, is the school's support to reduce the dropout by supporting persistence of students to finish their graduation properly. It was further asserted by the teachers that the schools must create properly supportive classroom surroundings for students who must cope with the situations outside of school which do not assist them in their endeavors of academics. Apart from this, it was suggested that different strategies, methods and steps must be adopted by these schools so as to strengthen their schools by reducing the student dropouts. The interviews further revealed that by strengthening the educational programs, the schools are able to create an integrative and comprehensive approach to mention the development and success of the academics of students. The teachers also suggested strategies such as the introduction of individualized instruction to the students to study at their own way, in their own style and be successful. Further, an active 


\section{ELK ASIA PACIFIC JOURNAL OF SOCIAL SCIENCES}

ISSN 2394-9392 (Online); DOI: 10.16962/EAPJSS/issn.2394-9392/2014; Volume 2 Issue 2 (2016)

experiential learning is essential to overcome the limitation imposed by scarcity of time. Mentoring, apart from a mere academic assistance was judged to be the most crucial step which was needed in this regards.

The data also revealed that schools in Adilabad district are in fact, following certain strategies to overcome the issue of student dropouts. One of the teachers from Sri Sarada English Medium School stated that their school uses quality services and programs to meet the education, nutritional and health needs of students. The focus of the educational structure now focuses greater on lifelong learning, and enhancing communication, literacy skills and critical thinking. Mentorship, incentives to enhance attendance, conducting programs to motivate the involvement of parents, are among the focal points of schools in Adilabad, further supported by the adoption of the latest technologies. A major initiative which was revealed for strengthening educational programs, undertaken by St Antony C\&C High School was the alternative schooling program, with different choices that can lead to graduation with programs paying special attention to individual social requirements of students and academic needs for a diploma of high schools.

\section{Conclusion}

The present study concluded that the factors of socio economy, teacher-related factors, personal factors, curricula and pedagogy related factors, infrastructure related factors are the major factors influencing the dropout of students from the schools. Among the major challenges faced by these schools, are the incapacities to acknowledge that they were unable to support their teachers which further led to student attrition and dropouts.

The present study strongly recommends that these schools must provide greater academic performance and reputable moral ethos to both schools and teachers. The urgent requirement for the students, is the availability of a childfriendly environment and policies, along with innovative educational initiatives or programs. A special attention must be given to the relatively weaker students in school, and also initiating a follow-up program for bringing back the students who have dropped out.

The present study is restricted to high schools of Telangana district. A further extensive study of various schools, and geographical areas, will help to better bring out the reasons for the 


\section{ELK ASIA PACIFIC JOURNAL OF SOCIAL SCIENCES}

ISSN 2394-9392 (Online); DOI: 10.16962/EAPJSS/issn.2394-9392/2014; Volume 2 Issue 2 (2016)

increasing incidence of student attrition and dropouts.

\section{References:}

1. Gouda, S. \& Sekher, T.V. (2014). Factors Leading to School Dropouts in India: An Analysis of National Family Health Survey-3 Data. Journal of Research \& Method in Education (IOSR-JRME), 4(6), pp. 75-83.

2. School Dropout Rate Higher in T State. Indian Express. July 2014. Retrieved from:

http://www.newindianexpress.com/states/tela ngana/School-Dropout-Rate-Higher-in-TState/2014/07/06/article2317136.ece

3. Arif, G.M. and Najum, U.S. Production of Cognitive and Life Skills in Public, Private, and NGO Schools in Pakistan. Pakistan Development Review (PDR), 42: 1 Spring. Pp. 1-28. 2003.

4. Jana, M., Khan, A., Chatterjee, S., Sar, N. \& Das, A. (2014). Dropout Rate at Elementary Level in Two Primary Schools of Backward Area, Paschim Medinipur, West Bengal. A Comparative Approach. American Journal of Educational Research, 2 (12), pp. 1288-1297.

5. Hussain A and Salfi N A (2011), Causes of Students' Dropout at Primary Level in
Pakistan: An Empirical Study, International Journal of Humanities and Social Science, Volume 1, No. 12.

6. Brown A A (2013), Parent Engagement Effects Student Drop Out, Author House, UK.

7. Anguiano K R (2006), Motivational Predictors of Continuing Motivation and Achievement for Early Adolescent Instrumental Music Students, ProQuest, Ann Arbor, pp 7.

8. Thyer B (2009), The Handbook of Social Work Research Methods, SAGE Publications, London.

9. Wagle, D. (2012). Dropout of Children from schools in Nepal, Norwegian University of Science and Technology

10. Radcliffe, P.M., Huesman, R.L., Kellogg, J.PP. (2006). Modeling the Incidence and Timing of Student Attrition: A Survival Analysis Approach to Retention Analysis. Conference of AIRUM, Bloomington, MN November 2-3.

11. Pratham Delhi (2008), Department of Human Development and childhood studies, Survey report reasons for drop out amongst 


\section{ELK ASIA PACIFIC JOURNAL OF SOCIAL SCIENCES}

ISSN 2394-9392 (Online); DOI: 10.16962/EAPJSS/issn.2394-9392/2014; Volume 2 Issue 2 (2016)

children living in slum areas of Delhi. Lady Irwin College

12. Gonindaraju,R., and Venkatesan,S., (2010), A Study on School Drop-outs in Rural Settings, Psychology, Vol 1 (1), pp. 45-53.

13. Redmond, B., Quin, S., Devitt, C., \& Archbold, J. (2011). MAA qualitative investigation into the reasons why students exit from the first year of their programme and UCD.

14. Sharma, Ruchita, Shubhangna Sharma and Shipra Nagar, (2007), "Extent of Female School Drop outs in Kangra District of Himachal Pradesh", Journal of Social Science, 15(3): 201-204.

15. Pandita R (2015), Enrolment \& Dropout Percentage among Boys \& Girls up to Secondary Level in India: A Comparative Study. International Letters of Social and Humanistic Sciences, Vol. 8 (2).

16. Pratinidhi, A.K., Warerkar S.V and S.G. Garad, (1992), "A study of school dropouts in an urban slum community", Demography India, vol. 21 No.2 pp. 301-305.

17. Kandasamy,V., Smarandache.F., Amal,K., and Kandasamy,K., (2013), Fuzzy
Analysis of School Dropouts and Their Life After, ohio, Education Publisher Inc.

18. Chugh S (2011), Dropout in secondary education - a study of children living in slums of Delhi. National University of Educational Planning and Administration

19. Oliha Josephine, A., \& Audu Vivian, I. (2014), Counseling Against Dropout Among Secondary School Students in EDO state, International Journal of Education and Practice, Pak Publishing Group.

20. C. Pramanik, V. Nangia (2010) Primary School Drop Outs in India, ICERI2010 Proceedings, pp. 5151-5159.

21. Jeynes WH (2007)_ The Relationship between parental involvement and urban secondary school Academic achievement. Ameta-analysis, urban Education 42: 82-110. 
List of Figures

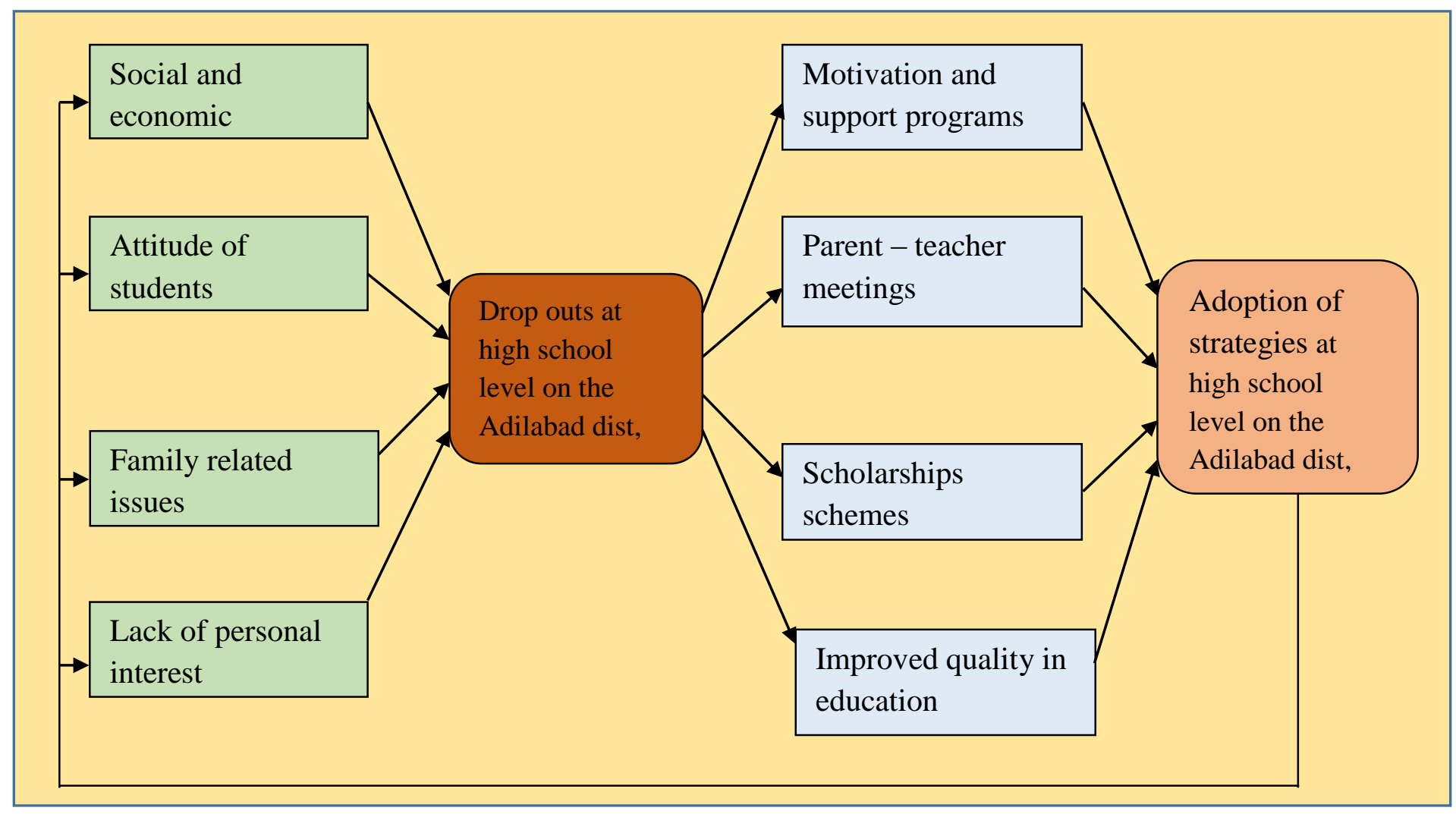

Figure 1: Conceptual framework

Source: Author 